Review

\title{
Mammalian Sperm Fertility Related Proteins
}

\author{
Ali Ashrafzadeh${ }^{1}$, Saiful Anuar Karsani² and Sheila Nathan ${ }^{1 凶}$ \\ 1. School of Biosciences and Biotechnology, Faculty of Science and Technology, University Kebangsaan Malaysia, Selangor, Malaysia; \\ 2. Institute of Biological Sciences, Faculty of Science, University of Malaya, Kuala Lumpur, Malaysia.
}

$\square$ Corresponding author: Sheila Nathan, DPhil. School of Biosciences and Biotechnology, Faculty of Science and Technology, Universiti Kebangsaan Malaysia, 43600 Bangi, Selangor DE, Malaysia. Tel: +603-89213862 Fax: +603-89252698 Email: sheila@ukm.my.

(C) Ivyspring International Publisher. This is an open-access article distributed under the terms of the Creative Commons License (http://creativecommons.org/ licenses/by-nc-nd/3.0/). Reproduction is permitted for personal, noncommercial use, provided that the article is in whole, unmodified, and properly cited.

Received: 2013.04.03; Accepted: 2013.07.23; Published: 2013.09.23

\begin{abstract}
Infertility is an important aspect of human and animal reproduction and still presents with much etiological ambiguity. As fifty percent of infertility is related to the male partner, molecular investigations on sperm and seminal plasma can lead to new knowledge on male infertility. Several comparisons between fertile and infertile human and other species sperm proteome have shown the existence of potential fertility markers. These proteins have been categorized into energy related, structural and other functional proteins which play a major role in sperm motility, capacitation and sperm-oocyte binding. The data from these studies show the impact of sperm proteome studies on identifying different valuable markers for fertility screening. In this article, we review recent development in unraveling sperm fertility related proteins.
\end{abstract}

Key words: proteomics, sperm, fertility, protein, infertility.

\section{Introduction}

Mammalian fertility is dependent on the orchestrated complex reactions beginning with spermatogenesis in the testes right through sperm-oolemma penetration [1, 2]. Any defect within this multi-step process can result in infertility or sub-fertility. Following spermatogenesis, sperm that leaves the testes is immotile and infertile. During its journey from the epididymis until it encounters an oocyte, the sperm undergoes several biochemical and physiological changes [3-6]. For example, several epididymal and accessory gland secreted proteins are added to the sperm along different parts of the male reproduction tract [4, 7-10]. Upon reaching the female reproduction tract, the sperm needs to be hyper-activated in order to acquire the competency to reach the oocyte, bind to and penetrate the zona pellucida and finally interact with and penetrate into the oolemma. Hyper-activation is acquired by capacitation within the female reproduction tract through the release of decapacitation proteins from the sperm membrane as well as a series of biochemical reactions related to sperm motility $[2,5,11-13]$. Sperm-zona binding is mediated by several proteins and glycoproteins which trigger the acrosome reaction to facilitate sperm-zona penetration [14, 15]. During this reaction, several proteins responsible for sperm-oolemma binding and penetration are exposed into the equatorial region of the sperm membrane $[5,16,17]$. At this point, the sperm is unable to undergo transcription and translation, hence, peripheral proteins and post-translational modifications play a major role in sperm fertility [18, 19].

The leading cause of infertility and sub-fertility in men is still poorly understood. A number of different studies have attempted to shed more light on the issues and defects that underlie this problem. One approach to unraveling the importance of sperm-related proteins would be to compare diseased sperm (Asthenozoospermic, Globozoospermic or Oligoasthenoteratozoospermic sperm) with normozoospermic sperm at the proteome level. Proteins which may be contributing to the defects in patients can be validated using genotypic knock out animal models, anti-protein antibodies and enzymatic protein cleavage or by the introduction of recombinant sperm proteins as biological antagonists. 
Proteomics approaches are promising in the identification of proteins associated with sperm fertility. In this article we have inventoried the current literature relating to sperm fertility proteins identified using the above mentioned approach, as available from several resources (Science Direct, Wiley Interscience, Oxford Journals and Medline). Protein fertility-related function(s) and sub-cellular location(s) are proposed based on Gene Ontology annotation of the Swiss Prot database.

\section{Sperm Motility and Differentiation Related Proteins}

Three different studies on proteomics-based comparison between low motile asthenozoospermic sperm and normal sperm revealed thirty four proteins of interest [20-22]. A further study comparing normal sperm with completely infertile globozoospermic sperm i.e. round-headed sperm with defects in differentiation identified thirty five regulated proteins [23]. Proteins related to sperm motility and differentiation are categorized into (i) energy related enzymes in mitochondrial and glycolytic pathways, (ii) structural proteins such as outer dense fiber and a-kinase anchoring proteins (AKAPs) in the flagella, and (iii) activating signal transducers e.g. protein kinase-A like (PKA) and serine-threonine-tyrosine kinase/ phosphatases [24].

\section{(i) Energy Related Enzymes}

ATP is a critical component for sperm motility and is produced as a result of mitochondrial oxidative phosphorylation and local energy production during glycolysis. Several sperm specific isoforms of glycolytic enzymes such as lactate dehydrogenase (LDH), hexokinase and testis specific glyceraldehyde-3-phosphate dehydrogenase (GAPD-S) are fibrous sheets associated with local energy production.
Dynein ATPase in the axonem uses this ATP to produce energy for flagella beating [24]. A comparison between asthenozoosperic and normal sperm showed suppression of isocitrate dehydrogenase subunit a (IDH-a), a TCA cycle enzyme, while phosphoglycerate mutase-2, triosephosphate isomerase and oxaloacetate transaminase- 1 were over expressed. This might be a compensatory mechanism to overcome a shortage in other enzymes [22]. Other sperm motility-related enzymes are testis specific isomer of glycerol kinase2 (GKP2), succinyl-CoA:3-ketoacid co-enzyme A transferase 1 [20], cytochrome c oxidase subunit $6 \mathrm{~B}$, dihydrolipoamide dehydrogenase precursor, fumarate hydratase precursor and sulfur transferase [21]. Almost all of these enzymes catalyze energy production pathways and ATP production which is a prerequisite for sperm movement. Table 1 summarizes the sperm energy related proteins.

\section{(ii) Structural Proteins}

Cytoplasmic actin and tubulin- $\alpha-2$ chains are cytoskeleton proteins involved in cell movement, signal transduction and membrane shape maintenance. Expression of these proteins is down regulated in globozoospermic round headed infertile sperm [23]. Defects in the outer dense fibers and a-kinase anchor proteins (AKAPs), the main flagella proteins, can significantly affect sperm motility (Table 2). Similarly, defects in axonemal components such as tektin and dyneins were shown to be the cause of sperm immobility [24]. Outer dense fiber protein 2 (ODF2) is an abundant centrosomal scaffold component and is necessary to maintain sperm flagella elasticity and tensile strength. Down regulation of ODF2 expression in globozoospermic sperm reveals its modulator role in sperm motility [23].

Table I. Energy Related Enzymes.

\begin{tabular}{|c|c|c|c|c|c|c|}
\hline Enzyme name & Access code & Enzyme Code & Symptoms & Protein regulation & Location & Reference \\
\hline $\begin{array}{l}\text { Isocitrate dehydrogenase subunit a } \\
\text { (IDH- a) }\end{array}$ & P50213 & $\mathrm{EC}=1 \cdot 1.1 .41$ & Asthenozoospermia & Down & Mitochondria & [22] \\
\hline Phosphoglycerate mutase 2 & P15259 & $\mathrm{EC}=5.4 .2 .1$ & Asthenozoospermia & $\mathrm{Up}$ & Cytosol & [22] \\
\hline Triose phosphate isomerase (TPIS) & P60174 & $\mathrm{EC}=5 \cdot 3.1 .1$ & Asthenozoospermia & $\mathrm{Up}$ & Cytosol & {$[20,22]$} \\
\hline Triose phosphate isomerase (TPIS) & P60174 & $\mathrm{EC}=5.3 .1 .1$ & Globozoospermia & Down & Cytosol & {$[23]$} \\
\hline Glutamate oxaloacetate transaminase- 1 & P17174 & $\mathrm{EC}=2.6 .1 .1$ & Asthenozoospermia & $\mathrm{Up}$ & Cytosol & [22] \\
\hline Fumarate hydratase precursor & P07954 & $\mathrm{EC}=4 \cdot 2 \cdot 1 \cdot 2$ & Asthenozoospermia & $\mathrm{Up}$ & $\begin{array}{l}\text { Mitochondria } \\
\text { \& Cytosol }\end{array}$ & [21] \\
\hline Cytochrome c oxidase subunit $6 \mathrm{~B}$ & Q7L1R4 & & Asthenozoospermia & Down & Mitochondria & {$[21]$} \\
\hline Glycerol kinase, testis specific 2 (GKP2) & Q14410 & $\mathrm{EC}=2 \cdot 7 \cdot 1.30$ & Asthenozoospermia & $\mathrm{Up}$ & - & [20] \\
\hline $\begin{array}{l}\text { Succinyl-CoA:3-Ketoacid co-enzyme A } \\
\text { transferase } 1 \text { (OXCT1) precursor }\end{array}$ & P55809 & $\mathrm{EC}=2.8 .3 .5$ & Asthenozoospermia & $\mathrm{Up}$ & Mitochondria & [20] \\
\hline $\begin{array}{l}\text { Glycealdehyde-3-phosphate dehydro- } \\
\text { genase, testis specific (GAPD-S) }\end{array}$ & Q64467 & $\mathrm{EC}=1 \cdot 2 \cdot 1 \cdot 12$ & $\begin{array}{l}\text { Knock-out Genotype } \\
\text { Mice }\end{array}$ & & Cytosol & {$[24]$} \\
\hline
\end{tabular}


Table 2. Flagella related proteins.

\begin{tabular}{llllll}
\hline Protein name & Access code & \multicolumn{1}{c}{ Symptoms } & Protein regulation & Location & Reference \\
\hline Outer dense fiber protein 2 (ODF2) & Q5BJF6 & $\begin{array}{l}\text { Globozoospermia } \\
\text { \& } \\
\text { Asthenozoospermia }\end{array}$ & Down & Flagella & [22, 23] \\
Tektin 1 (TEKT1) & Q969V4 & Asthenozoospermia & Down & Flagella & {$[20]$} \\
Septin 4 (SEPT4) & O43236 & Asthenozoospermia & Down & Annulus & {$[26]$} \\
Testis anion transporter 1 (Tat1) & Q96RN1 & Asthenozoospermia & Down & Annulus & {$[26]$} \\
Secretory actin-binding protein (SABP) & P12273 & Asthenozoospermia & Up & Midpiece & {$[50]$} \\
Tubulin beta-2C chain (TUBB2C) & P68371 & Asthenozoospermia & Down & Flagella & {$[20]$} \\
Isoform 1 of tubulin a-2 chain & - & Globozoospermia & Down & Flagella & {$[23]$} \\
Isoform 2 of tubulin a-2 chain & - & Globozoospermia & Down & Flagella & {$[23]$} \\
Similar to a-tubulin & - & Globozoospermia & Down & Flagella & {$[23]$} \\
a-tubulin isotype H2-a & P68366 & Globozoospermia & Down & Flagella & {$[23]$}
\end{tabular}

Annulus is an electron-dense septin-based ring-shape structure between the midpiece and principle piece of sperm flagella. Septins, as the main component of the annulus, are small GTPases which form homo/heteropolymers associated with cell membranes, actin and cytoskeleton microtubules. Septin4 null mice have null annulus sperm with bent/detached flagella in the midpiece-principle piece junction which together with mitochondrial dislocation, leads to asthenozoospermia and infertility. As testis anion transporter 1 (Tat1) and septin4 are co-expressed during spermatogenesis, Tat1 null mice show the same symptoms as septin4 null animals [25]. In an individual with moderate asthenozoospermia, $97 \%$ of his sperm did not contain Tat1, septin 4 and septin7 at the annulus even though expression of all these proteins was normal. This suggests mislocalization of these proteins in his sperm [26].

\section{(iii) Activating Signal Transducers}

Capacitation is the series of biochemical reactions in sperm that is related to sperm fertility and hyper-activation. During capacitation, sperm membrane fluidity increases due to cholesterol efflux introduced by bicarbonate secreted in the uterus. The cholesterol which is released descends into the albumin which is abundant in both seminal fluid and the uterus [3, 27]. Bicarbonate activates soluble adenylate cyclase (sAC) (Table 3) and subsequently cAMP production which assists sperm protein phosphorylation by protein kinase-A (PKA) [3]. Post-translational protein phosphorylation by PKA and tyrosine kinase has a pivotal role in initiation, maintenance and control of sperm motility. Compartmentalization of sAC into distinct parts of the cell leads to activation of PKA by locally produced cAMP. sAC is associated with the fibrous sheet in sperm tail and its requirement for sperm motility has previously been demonstrated [24]. Intriguingly, an insulin-dependent autocrine mechanism triggers sperm capacitation and acrosome reaction in pigs. Insulin and insulin receptor $\beta$ are located in the midpiece of porcine sperm whilst insulin is also found in the acrosome [28]. Structural proteins such as CatSper 1, 2, 3 and 4 (cation channel, sperm related protein family) are located on the sperm tail and are involved in sperm hyper-activation and fertility by Calcium influx [24].

\section{Sperm-Zona Pellucida Interaction and Sperm-Oolemma Penetration Proteins}

The zona pellucida is comprised of sulfated glycoproteins such as ZP1, ZP2 and Zp3 which are produced by oocyte or granulosa cells. ZP3's main role appears to be that of sperm receptor (Table 4) [29]. Sperm-zona pellucida binding includes several protein-protein and protein-carbohydrate interactions. The molecular model for sperm-oocyte binding in mouse has been reviewed recently and proposed the existence of lectin-like proteins on the sperm plasma membrane which bind to ZP1, ZP2 and ZP3 [30]. Several sperm proteins are known to bind to zona pellucida glycoproteins. $\beta$ 1,4-galactosyltransferase 1 (GalT), an integral sperm membrane protein on the acrosome cap, plays a role as signal transducer through binding to the n-acetyl glucosamine moiety of ZP3. SP47 or SDE1 is an epididymal protein secreted from the epididymis caput and covers the apical region of sperm head. GalT1 and SP47 collaborate in initial sperm docking on the zona pellucida $[29,31]$ where SP47 binds to the sialylated and sulfated carbohydrates of ZP3. Hepatic lectin 2/3 which is located on the sperm head and flagella of human and rat sperm binds to the galactose moiety of ZP3 [31]. Spermadhesin or AQN-3 is a porcine protein which plays a role in sperm zona pellucida binding. AQN3, secreted by the epididymis, is located on the acrosome region as an integral membrane protein and participates in the primary zona-binding as a heparin-binding protein [32, 33]. Membrane associated $\mathrm{N}$-acetylglucosaminidase is located in the acrosome region and seems to play a role in initial sperm-zona binding in humans [34]. 
Table 3. Signal transducer proteins.

\begin{tabular}{|c|c|c|c|c|c|c|}
\hline Protein name & Access code & Symptoms & $\begin{array}{l}\text { Protein } \\
\text { regulation }\end{array}$ & Location & Protein Function & Reference \\
\hline $\begin{array}{l}\text { Dihydrolipoamide } \\
\text { dehydrogenase } \\
\text { (DLD) precursor }\end{array}$ & P09622 & Asthenozoospermia & Up & Mitochondria & $\begin{array}{l}\text { Hyperactivation of sperma- } \\
\text { tazoa during capacitation } \\
\text { and acrosome reaction }\end{array}$ & {$[21]$} \\
\hline $\begin{array}{l}\text { Inositol-1(or } 4)- \\
\text { monophosphatase }\end{array}$ & P29218 & Asthenozoospermia & Up & Cytosol & $\begin{array}{l}\text { Key enzyme of the } \\
\text { phosphatidyl inositol sig- } \\
\text { naling } \\
\text { pathway }\end{array}$ & [21] \\
\hline $\begin{array}{l}\text { S100 calcium binding } \\
\text { protein A9 }\end{array}$ & P06702 & Asthenozoospermia & Down & - & Ca binding protein & {$[21]$} \\
\hline CatSper $1^{*}$ & Q91ZR5 & Knock-out gene mice & & $\begin{array}{l}\text { Fibrous sheet } \\
\text { of flagella }\end{array}$ & $\begin{array}{l}\text { Ca influx to trigger tyrosine } \\
\text { phosphorylation }\end{array}$ & {$[24]$} \\
\hline CatSper 2 & A2ARP9 & Knock-out gene mice & & $\begin{array}{l}\text { Fibrous sheet } \\
\text { of flagella }\end{array}$ & $\begin{array}{l}\text { Ca influx to trigger tyrosine } \\
\text { phosphorylation }\end{array}$ & {$[24]$} \\
\hline CatSper 3 & Q80W99 & Knock-out gene mice & & $\begin{array}{l}\text { Fibrous sheet } \\
\text { of flagella }\end{array}$ & $\begin{array}{l}\text { Ca influx to trigger tyrosine } \\
\text { phosphorylation }\end{array}$ & {$[24]$} \\
\hline CatSper 4 & Q8BVN3 & Knock-out gene mice & & $\begin{array}{l}\text { Fibrous sheet } \\
\text { of flagella }\end{array}$ & $\begin{array}{l}\text { Ca influx to trigger tyrosine } \\
\text { phosphorylation }\end{array}$ & {$[24]$} \\
\hline $\begin{array}{l}\text { Soluble adenylyl cyclase } \\
\text { (sAC) }\end{array}$ & Q8C0T9 & Knock-out gene mice & & $\begin{array}{l}\text { Fibrous sheet } \\
\text { of flagella }\end{array}$ & cAMP production & {$[24]$} \\
\hline Tssk $4^{* *}$ & Q6SA08 & - & & $\begin{array}{l}\text { Head, acrosome and } \\
\text { whole flagella }\end{array}$ & $\begin{array}{l}\text { May involve in a signalling } \\
\text { pathway }\end{array}$ & [59] \\
\hline Tssk1 & Q61241 & - & & $\begin{array}{l}\text { Head, acrosome and } \\
\text { whole flagella }\end{array}$ & $\begin{array}{l}\text { May involve in a signalling } \\
\text { pathway }\end{array}$ & [59] \\
\hline PCSK $4 * * *$ & P29121 & Knock-out gene mice & & $\begin{array}{l}\text { Sperm membrane on } \\
\text { the acrosomal area }\end{array}$ & $\begin{array}{l}\text { Enzymatic activation of } \\
\text { precursor proteins }\end{array}$ & {$[66]$} \\
\hline
\end{tabular}

Table 4. Sperm-Zona Binding Proteins.

\begin{tabular}{llll}
\hline Protein name & Access code & Location & Zona Receptor (binding moiety) \\
\hline$\beta 1,4$-galactosyltransferase 1 (GalT) & P15535 & Apical Region & ZP3 (N-acetyl glucosamine) \\
Lactadherin (SP47/ SED1) & P21956 & Apical Region & ZP3 (Sialylated \& Sulfated carbohydrate) \\
Hepatic lectin R2/3 (rHL-2) & P08290 & Head \& Flagella & ZP3 (Galactose moiety) \\
Spermadhesin (AQN-3) & P24020 & - & ZP3 (Carbohydrate moiety) \\
Angiotensin-converting enzyme (ACE) & P09470 & Cell Membrane & -
\end{tabular}

A proteome investigation of infertile human sperm resulted in the identification of a $57 \mathrm{kDa}$ protein in the apical region of non-acrosome reacted sperm. During the acrosome reaction, this protein migrates to the equatorial region and contributes to sperm-oocyte penetration (Table 5). This protein is absent in the sperm of $80 \%$ of infertile patients and is dramatically down regulated in the other 20\% [35]. Inner acrosomal membrane protein (IAM38) and zona-pellucida binding protein 2 (ZPBP2) are located in the inner part of the acrosome and thought to interact with zona glycoproteins during sperm-oocyte penetration [36]. Zonadhesin is the inner-acrosomal protein in porcine sperm which is involved in sperm-oolemma interaction [31]. Mice sperm-oolemma penetration was inhibited by anti-equatorin (MN9-antigen, a transmembrane sialoglycoprotein) antibody without affecting sperm mo- tility or zona binding, which proves its role in sperm-oocyte penetration [36]. Angiotensin converting enzyme genetic knock-out mice are infertile due to deficiency in sperm-zona pellucida binding [33].

IZUMO is an integral sperm membrane protein and is the testis/male germline specific member of the immunoglobulin super-family and is located in the inner acrosomal membrane and equatorial region [29]. IZUMO can interact with other cell adhesion molecules such as CD9 and CD81 that play a role in sperm-oolemma penetration. CD9 and CD81 are members of the hydrophobic membrane protein family called tetraspanins which have four transmembranes and two extra cellular loops. These proteins are in the high cholesterol domain of the oolemma and make a network with kinase and integrins in the lipid rafts to control sperm oolemma interaction and penetration [36]. 
Table 5. Sperm-Oolemma Penetration Related Proteins.

\begin{tabular}{|c|c|c|c|}
\hline Protein name & Access code & Location & Reference \\
\hline Sperm inner acrosomal membrane protein (IAM38) & Q2PMM0 & Inner acrosomal membrane & [36] \\
\hline Zona-pellucida binding protein 2 (ZPBP2) & Q6X784 & Inner acrosomal membrane & [36] \\
\hline Zonadhesin & Q28983 & Inner acrosomal membrane & [31] \\
\hline Equatorin (MN9) & B7SXT5 & Integral membrane protein & {$[36]$} \\
\hline IZUMO family members & - & Integral membrane protein & {$[36]$} \\
\hline Fertilin subunit beta (ADAM 2) & Q99965 & Integral membrane protein & [38] \\
\hline Cyritestin (ADAM 3) & Q62287 & Integral membrane protein & {$[40]$} \\
\hline CRISP1 & Q03401 & Equatorial segment in capacitated sperm & [36] \\
\hline CRISP2 & P16563 & Inner acrosome membrane & [36] \\
\hline ERp57 & P30101 & $\begin{array}{l}\text { Acrosome, tail and after acrosome reaction in } \\
\text { equatorial segment }\end{array}$ & {$[45]$} \\
\hline Sperm lysozyme-like protein 1 (mSLLP1)* & Q9D9X8 & Equatorial part of acrosome reacted sperm & [29] \\
\hline Spermatozoa acrosome membrane-associated protein 1 (SPACA1) & Q9HBV2 & Equatorial part of capacitated sperm & [23] \\
\hline Guanylyl cyclase receptor G & Q6TL19 & Acrosome cap \& equatorial segment & {$[60]$} \\
\hline
\end{tabular}

The proteolytic products of testes originated "a-disintegrin and a-metalloprotease" family members (ADAMs) such as disintegrin, cysteine rich domain and epidermal growth factor (EGF) are found on human and mice sperm membrane. These proteins are involved in sperm-oocyte penetration and sperm migration in the oviduct [37]. In humans, ADAM 2 binds to the integrin receptor of oolemma (integrin $\alpha_{6} \beta_{1}$ ) and functions in sperm-oocyte interaction [29, 38]. Additionally, ADAM 18 (tMDC III) contains the integrin binding motif which might be involved in sperm-oocyte binding in humans [39]. In porcine, ADAM 2 (fertilin $\beta$ ) has zona-binding affinity and may act in sperm-zona pellucida interaction [32]. ADAM 3 null mice showed impairment in sperm-zona pellucida binding and sperm migration to the oviduct [31, 40].

Neural cadherin ( $\mathrm{N}$-cadherin) is a transmembrane glycoprotein located in the equatorial segment of human acrosome-reacted sperm and plays a role in sperm-oolemma interaction [41]. Two glycoproteins of the cystein-rich secretory protein (CRISPs) family members are associated with sperm-oolemma penetration. CRISP1 has been found in the equatorial segment of capacitated sperm. Blocking CRISP1 by antibodies reduced the zona penetration in fertile mice although this might be compensated by other members of CRISPs like CRISP2. CRISP2 (TXP2) is an intra-acrosomal protein originated from the testis [36]. CRISP1 is secreted in an androgen-dependent manner in the dorsal epididymis and then relocated to the sperm head. It has two domains, the plant pathogenesis-related domain (PR-1) and cystein rich domain (CRD). PR-1 is in the N-terminal region and contains the signature 2 (S2) which is an evolutionary conserved 12 amino acid region and plays a role in sperm-oocyte penetration. CRD is in the C-terminal region of CRISP1 that has ion channel regulating activity. This domain is assigned as decapacitation factor which acts by inhibiting tyrosine phosphorylation and ion influx. Two groups of CRISP1 have been found on murine sperm, one of which is loosely bound to the membrane whilst the other is tightly bound. During capacitation, the first group is released from the sperm surface and this might be related to elimination of its decapacitation activity. The other membrane attached CRISP1 is located on the dorsal part of capacitated intact sperm and participates in sperm-zona pellucida binding. After acrosome reaction, CRISP1 migrates to the equatorial segment to play a role in sperm-oocyte penetration. Testicular CRISP2 is located in the acrosome region and may act in Calcium influx during capacitation and sperm-oocyte fusion [42-44].

Several members of the protein disulfide isomerase (PDI) family (ERp57, ERp72, PDI and P5) have been found on the equatorial segment of murine spermatozoa with roles in protein refolding which might trigger sperm-oocyte fusion. Since IZUMO and CD9 have disulfide bonds in their extracellular domain, they might be substrates of endoplasmic reticulum resident protein 57 (ERp57) [29]. ERp57 is found in the acrosome and flagella of non-acrosome reacted sperm and migrates to the equatorial segment after acrosome reaction. ERp57 is down regulated in infertile sperm and blocking ERp57 with anti-ERp57 antibody inhibits sperm-oocyte penetration. During capacitation, ERp57 may undergo post-translational modification, probably phosphorylation, to gain its functional conformation [45].

Sperm acrosome membrane-associated protein 3, also known as mouse sperm lysozyme-like protein 1 (mSLLP1), is located on human and mice sperm head and migrates to the equatorial segment following 
acrosome reaction. This protein plays a role in sperm-oocyte fusion through its N-acetylglucosamine-binding residue [29]. Spermatozoa acrosome membrane-associated protein 1 (SPACA1), which is the glycoprotein receptor in the equatorial segment, has a role in sperm oocyte fusion [23].

\section{Acrosome Biogenesis and Acrosome Reaction Proteins}

Family members of "sperm protein associated with the nucleus on the X chromosome" (SPANX-A, B and $C$ ) which are expressed in post-meiotic spermatids, play a role in acrosome biogenesis and are down regulated in globozoospermic sperm [23]. Furthermore, sperm acrosome membrane-associated protein 1 (SPACA1) is virtually absent in the globozoospermic sperm leading to structural defects in sperm differentiation which affects sperm-oocyte fusion [23]. The acrosome reaction inducer in mammalian cells is still obscure but zona binding protein 3 (ZP3) is suspected to be an acrosome reaction activator. In mice $\beta 1$, 4-galactosyltransferase (GalT) is the ZP3 ligand on sperm membrane and GalT-null sperm fail to penetrate the zona pellucida [3]. Progesterone exists in the follicular fluid at micromolar concentrations. During sperm-zona reaction, sperm is exposed to progesterone which sensitizes the sperm by Ca flux and tyrosine phosphorylation leading to an induction of acrosome reaction by zona binding proteins such as human ZP2, ZP3 and ZP4 [24, 46]. Since sperm is transcriptionally and translationally inactive, progesterone affects sperm physiology through sperm membrane receptors instead of nuclear receptors [3, 47-49].

Seminal plasma secretory actin-binding protein (SABP) is located in the mid piece of sperm and is over-expressed in infertile individuals. For example, oligoasthenoteratozoospermic sperm, with few morphologically abnormal and slow motile sperm, showed significantly higher SABP than asthenozoospermic samples. SABP binds to actin which is associated with capacitation and acrosome reaction and is the main cytoskeletal human sperm protein in head, midpiece and tail. SABP acts similarly to anti-actin antibody which significantly suppresses the zona-induced acrosome reaction and motility [50].

\section{Nuclear Proteins}

Protamine 1 and the family members of protamine 2 (P2, P3 and P4) are the most abundant sperm nuclear proteins. They are twice as small as histones, highly basic and contain a significant number of cysteins. Testis/sperm-specific histone 2B (TSH2B) is found to be over-expressed in infertile men and negatively correlated with protamine abundance [51]. The consequences of replacing histones with protamines during spermatogenesis are nucleus condensation to a hydrodynamic shape and maintenance of DNA integrity [52]. In infertile men and also smokers, the $\mathrm{P} 1 / \mathrm{P} 2$ ratio which is $1 / 1$ in fertile individuals, is increased as a consequence of under-expression of P2. In this case, low fertility is a result of DNA fragmentation observed in the sperm samples [52-54]. DNA fragmentation has been shown to be negatively correlated with sperm fertility [55].

\section{Peripheral Proteins}

Some sperm proteins are peripheral i.e. produced outside the sperm and then attach to the sperm. These proteins might originate from testicular tissues (seminiferous tubules), epididymis and accessory glands. Several lines of evidence support the claim that some proteins are peripheral. First, the proteins can be easily removed from the sperm surface by high salt or Percoll gradient solutions. Secondly, protein function can be restored by sperm exposure to the purified protein and thirdly, these peripheral proteins are detectable in seminal plasma. It has been demonstrated that some of these proteins are fertility related based on different expression levels in fertile and infertile individuals [56-59].

Epididymosomes are membranous vesicles secreted by epididymal epithelium cells and contain numerous proteins that are selectively transferred to the sperm and act in sperm maturation and fertility [56]. Eppin is an epididymal protease inhibitor found on the acrosome and tail of human sperm which migrates to the equatorial segment after acrosome reaction. Blocking eppin with antibodies inhibited the human sperm acrosome reaction [57]. Beta defensin 126 (DEFB 126) is an epididymal protein which covers the whole sperm head of Macaque monkeys and plays a main role in sperm cervical mucus penetration [58].

The existence of the testis-specific serine/threonine kinase (Tssk) has been demonstrated at different locations of mice and human sperm. The role of Tssks in fertility were demonstrated by the sterile phenotype of Tssk1/Tssk2 knock out and Tssk6 null mice [59]. Another peripherally expressed protein is the guanylyl cyclase receptor-G (hGC-G) which is expressed in human testis. Its receptor-like peptide is on the acrosome cap and equatorial segment of the mature sperm and plays a role in zona binding in humans [60].

Glycosaminoglycans, especially heparin, play crucial roles in sperm capacitation, acrosome reaction, and sperm-oocyte penetration, mediated by heparin-binding proteins (HBPs) which are the main constituents of human seminal plasma. Among these HBPs, structural proteins like semenogelin I, se- 
menogelin II and fibronectin are abundant in seminal plasma and trap the sperm in the gel to protect them from physical damage. The most abundant HBP is lactoferrin which seems to be the major antigen on the surface of the sperm membrane and acts as an antimicrobial and immunoprotectant agent for sperm in the female reproductive tract [27]. In bovine non-capacitated sperm, lectin-like heparin binding proteins such as bovine seminal plasma protein family members (BSP A1, BSP A2, BSP A3 and BSP-30-kDa), bind to fucose, an oviduct epithelial trisaccharide, to produce a sperm reservoir in the oviduct prior to ovulation. These sperm binding proteins play a crucial role in fertility by maintaining sperm motility and viability during storage. These proteins contain an evolutionary conserved domain which binds to sperm membrane choline phospholipids upon ejaculation although the heparin binding domains are dissimilar. This redundancy ensures sperm binding under different situations such as time of insemination and the different micro-environments of the female reproduction track [58, 61-63].

A comparison between fertile and infertile individuals also identified differences in the seminal fluid proteome which could be important in revealing the role of fertility proteins. The proteomic comparison of accessory glands fluid in thirty seven high fertile Holstein bulls showed different expression levels of twenty proteins related to fertilization, capacitation and sperm motility [64].

\section{Post-Translational Modification Proteins}

As sperm is a translational and transcriptionally inactive cell, post-translational modification (PTM) plays a crucial role in sperm activation and fertilization. S-nitrosylation and phosphorylation are two major PTMs which affect sperm fertility related proteins. S-nitrosylated sperm proteins, e.g. tubulin, glutathione s-transferase (GST), heat shock-related proteins (HSPs), A-kinase anchoring protein (AKAP) types 3 and 4 , voltage-dependent anion-selective channel protein 3 and semenogelin 1 and 2 are localized on the post-acrosomal region and throughout the flagellum [19]. Among these proteins, HSPs, tektin, tubulin and semenogelin 1 were confirmed to be sperm motility related [20-22]. The epididymal proteins HSP60, HSP90 and endoplasmin (Erp99) are located on the anterior part of the acrosome and chaperone key proteins in the sperm-zona reaction. These chaperone proteins might reassemble and render sperm-zona receptors ready for zona binding [29]. Recently HSP60 has been found in the midpiece and endoplasmic reticulum chaperone protein (GRP78) in the neck region of human sperm [65].

Phosphorylation also modifies sperm proteins such as gamma-tubulin. Hypo-phosphorylation and reduced expression of gamma-tubulin are related to low sperm motility [6]. Flagella calcium binding protein (CABYR) and fibrous sheet AKAP3 are highly tyrosine-phosphorylated during sperm capacitation leading to sperm hyper-activation. Sperm motility hyper-activation is influenced by phosphorylation of the post-pyruvate metabolic enzyme dihydrolipoamide dehydrogenase during hamster sperm capacitation [24].

Limited endoproteolysis of precursor proteins is a form of post-translational modification to activate proteins. Proprotein convertase subtilisin/kexin type 4 (PCSK4) also called protein convertase type 4 (PC4), is a member of one of nine families of calcium-dependent serine endoproteinases located on the acrosomal region of sperm membrane. PC4 has roles in sperm capacitation, hyper-activation and sperm-zona pellucida reaction. It functions through limited endoproteolysis of members of the ADAM family, proenkephalin, propituitary adenylate cyclase-activating peptide (proPACAP), insulin like growth factor-1 (IGF-1) receptor and hepatocyte growth factor receptor [66]. It is not clear yet to what extend endoproteolysis of ADAMs is correlated to fertility. The cleavage rate of ADAM 2 and ADAM 3 is shown to be different among individual mice with inositol polyphosphate 5-phosphatase null phenotype but is significantly correlated to each other. This may explain the identical endoproteolysis process of ADAM2 and ADAM 3 in mice [37].

\section{Challenges in Unraveling the Sperm Proteome}

Proteomic techniques such as 2D polyacrylamide gel electrophoresis (2D-PAGE), mass spectrometry (MS), and differential in gel electrophoresis (DIGE), have led to the identification of numerous sperm-specific proteins. A further advantage of applying proteomics based techniques on the study of sperm proteins is the ability to also study post-translational modification that control sperm processes and function. Nevertheless, there are still several limitations to understanding the proteome of mammalian species. Extraction of hydrophobic proteins such as membrane proteins and their direct identification using mass spectrometry analysis is still a big challenge. Generally, the use of anionic detergents such as SDS to extract membrane proteins prior to performing SDS poly acrylamide gel electrophoresis, in-gel tryptic digestion mass spectrometry can collectively identify a cohort of membrane proteins $[67,68]$. However, extraction and identification methods of intact hydrophobic proteins still requires further development.

Current techniques are still limited in making 
fully accurate measurements of all proteins present as separation of a complex mixture of protein and peptides still remains one of the most difficult challenges. Variations in study findings can be attributed to numerous factors, many of which are uncontrollable in current proteomic advances. Furthermore, researchers face numerous challenges in processing and analysing large datasets. As alluded to above, extraction and identification of membrane proteins is still a big challenge in proteomics. Although several protocols have been developed to identify the enzymatically digested membrane proteins by mass spectrometry, developing methods for identification of intact membrane proteins needs further efforts. Nevertheless, with the continuous advances made with bioinformatics programmes, it is expected that future proteomics studies should direct the interpretation of more robust data which hopefully, will lead to new knowledge on potential causes of sperm impairment and providing insights to its underlying mechanistic pathways.

\section{Conclusion}

Fertility is dependent on complex orchestrated biological reactions and is a bottle neck in the sustainability of mammalian populations. Every one of these biochemical reactions is controlled by various proteins with obvious importance but the exact role of these different proteins in male and female fertility is still unclear. Furthermore, comparisons between fertile and infertile sperm samples from different species revealed differences in protein expression. Nevertheless, current information about fertility related proteins is still not sufficient to propose diagnostic or prognostic protocols. Further efforts are needed to identify sperm proteins that would have an impact on fertility and unravel their physiological roles as well as establish new diagnostic methods for infertility.

\section{Abbreviations}

AKAP: a-kinase anchoring protein; PKA: protein kinase-A; LDH: lactate dehydrogenase; GAPD-S: glyceraldehyde-3-phosphate dehydrogenase testis specific; IDH-a: isocitrate dehydrogenase subunit $\mathrm{a}$; GKP2: testis specific isomer of glycerol kinase2; ODF2: outer dense fiber protein 2; Tat1: testis anion transporter 1; sAC: soluble adenylate cyclase; ZP: zona pellucida glycoprotein; GalT: $\quad \beta$ 1,4-galactosyltransferase 1; IAM38: inner acrosomal membrane protein; ZPBP2: zona-pllucida binding protein 2; CAM: cell adhesion molecule; ADAM: a disintegrin and a metalloprotease; EGF: epidermal growth factor; N-cadherin: Neural cadherin; CRISP: cyctein-rich secretory protein; PR-1: plant pathogenesis-related domain; S2: signature 2; CRD: cystein reach domain; ERp: endoplasmic reticulum resident pro- tein; PDI: protein disulfide isomerase; mSLLP1: mouse sperm lysozyme-like protein 1; SPACA1: spermatozoa acrosome membrane-associated protein 1; SPANX: sperm protein associated with the nucleus on the $X$ chromosome; SABP: seminal plasma secretory actin-binding protein; TSH2B: Testis/sperm-specific histone 2B; DEFB 126: Beta Defensin 126; Tssk: testis-specific serine/threonine kinase; hGC-G: guanylyl cyclase receptor-G; HBP: heparin-binding protein; BSP: bovine seminal plasma protein; PTM: post-translational modification; GST: glutathione s-transferase; HSP: heat shock-related protein; Erp99: endoplasmin; CABYR: calcium binding protein; PCSK4: proprotein convertase subtilisin/kexin type 4; PC4: protein convertase type 4; proPACAP: propituitary adenylate cyclase-activating peptide; IGF-1: insulin like growth factor-1.

\section{Competing Interests}

The authors have declared that no competing interest exists.

\section{References}

1. Rajender S, Avery K, Agarwal A. Epigenetics, spermatogenesis and male infertility. Mutat Res. 2011; 727: 62-71.

2. Mannowetz N, Wandernoth $\mathrm{P}$, Hornung J, Ruffing $U$, Raubuch $M$, Wennemuth G. Early activation of sperm by HCO3- is regulated hormonally in the murine uterus. Int J Androl. 2011; 34: 153-64.

3. Yoshida M, Kawano N, Yoshida K. Control of sperm motility and fertility: diverse factors and common mechanisms. Cell Mol Life Sci. 2008; 65: 3446-57.

4. Sato H, Taketomi Y, Isogai Y, Miki Y, Yamamoto K, Masuda S, et al. Group III secreted phospholipase A2 regulates epididymal sperm maturation and fertility in mice. J Clin Invest. 2010; 120: 1400-14.

5. Young C, Grasa P, Coward K, Davis LC, Parrington J. Phospholipase C zeta undergoes dynamic changes in its pattern of localization in sperm during capacitation and the acrosome reaction. Fertil Steril. 2009; 91: 2230-42.

6. Chan CC, Shui HA, Wu CH, Wang CY, Sun GH, Chen HM, et al. Motility and protein phosphorylation in healthy and asthenozoospermic sperm. J Proteome Res. 2009; 8: 5382-6.

7. Katagiri YU, Sato B, Yamatoya K, Taki T, Goto-Inoue N, Setou M, et al. GalNAc $\beta 1,3$-linked paragloboside carries the epitope of a sperm maturation-related glycoprotein that is recognized by the monoclonal antibody MC121. Biochem Biophys Res Commun. 2011; 406: 326-31.

8. Fàbrega A, Guyonnet B, Dacheux J-L, Gatti J-L, Puigmulé M, Bonet S, et al. Expression, immunolocalization and processing of fertilins ADAM-1 and ADAM-2 in the boar (Sus domesticus) spermatozoa during epididymal maturation. Reprod Biol Endocrinol. 2011; 9: 1-13.

9. Belleannée C, Labas V, Teixeira-Gomes A-P, Gatti JL, Dacheux J-L, Dacheux F. Identification of luminal and secreted proteins in bull epididymis. J Proteomics. 2011; 74: 59-78

10. Aitken RJ, Nixon B, Lin M, Koppers AJ, Lee YH, Baker MA. Proteomic changes in mammalian spermatozoa during epididymal maturation. Asian J Androl. 2007; 9: 554-64.

11. Jagan Mohanarao G, Atreja SK. Identification of capacitation associated tyrosine phosphoproteins in buffalo (Bubalus bubalis) and cattle spermatozoa. Anim Reprod Sci. 2011; 123: 40-7.

12. Zimmerman $S$, Sutovsky P. The sperm proteasome during sperm capacitation and fertilization. J Reprod Immunol. 2009; 83: 19-25.

13. Suarez SS. Control of hyperactivation in sperm. Hum Reprod Update. 2008; 14: 647-57.

14. Chiu PCN, Wong BST, Lee C-L, Lam KKW, Chung M-K, Lee K-F, et al. Zona pellucida-induced acrosome reaction in human spermatozoa is potentiated by glycodelin-A via down-regulation of extracellular signal-regulated kinases and up-regulation of zona pellucida-induced calcium influx. Hum Reprod. 2010; 25: 2721-33.

15. Zitta K, Wertheimer EV, Miranda PV. Sperm N-acetylglucosaminidase is involved in primary binding to the zona pellucida. Mol Hum Reprod. 2006; 12: 557-63.

16. Hirohashi N, Kamei N, Kubo H, Sawada H, Matsumoto M, Hoshi M. Egg and sperm recognition systems during fertilization. Dev Growth Differ. 2008; 50 Suppl 1: 221-38. 
17. Boerke A, Tsai PS, Garcia-Gil N, Brewis IA, Gadella BM. Capacitation-dependent reorganization of microdomains in the apical sperm head plasma membrane: Functional relationship with zona binding and the zona-induced acrosome reaction. Theriogenology. 2008; 70: 1188-96.

18. Mor V, Das T, Bhattacharjee M, Chatterjee T. Protein tyrosine phosphorylation of a heparin-binding sperm membrane mitogen (HBSM) is associated with capacitation and acrosome reaction. Biochem Biophys Res Commun. 2007; 352: 404-9.

19. Lefievre L, Chen Y, Conner SJ, Scott JL, Publicover SJ, Ford WCL, et al. Human spermatozoa contain multiple targets for protein S-nitrosylation: An alternative mechanism of the modulation of sperm function by nitric oxide? Proteomics. 2007; 7: 3066-84.

20. Siva AB, Kameshwari DB, Singh V, Pavani K, Sundaram CS, Rangaraj N, et al. Proteomics-based study on asthenozoospermia: differential expression of proteasome alpha complex. Mol Hum Reprod. 2010; 16: 452-62.

21. Martinez-Heredia J, de Mateo S, Vidal-Taboada JM, Ballesca JL, Oliva R. Identification of proteomic differences in asthenozoospermic sperm samples. Hum Reprod. 2008; 23: 783-91.

22. Zhao C, Huo R, Wang F-Q, Lin M, Zhou Z-M, Sha J-H. Identification of several proteins involved in regulation of sperm motility by proteomic analysis. Fertil Steril. 2007; 87: 436-8.

23. Liao T-T, Xiang Z, Zhu W-B, Fan L-Q. Proteome analysis of round-headed and normal spermatozoa by 2-D fluorescence difference gel electrophoresis and mass spectrometry. Asian J Androl. 2009; 11: 683-93.

24. Muratori M, Luconi M, Marchiani S, Forti G, Baldi E. Molecular markers of human sperm functions. Int J Androl. 2009; 32: 25-45.

25. Kissel H, Georgescu MM, Larisch S, Manova K, Hunnicutt GR, Steller H. The Sept4 septin locus is required for sperm terminal differentiation in mice. Dev Cell. 2005; 8: 353-64.

26. Lhuillier P, Rode B, Escalier D, Lores P, Dirami T, Bienvenu T, et al. Absence of annulus in human asthenozoospermia: Case Report. Hum Reprod. 2009; 24: 1296-303.

27. Kumar V, Hassan MI, Tomar AK, Kashav T, Nautiyal J, Singh S, et al. Proteomic analysis of heparin-binding proteins from human seminal plasma: a step towards identification of molecular markers of male fertility. J Biosci. 2009; 34: 899-908.

28. Carpino A, Rago V, Guido C, Casaburi I, Aquila S. Insulin and IR- $\beta$ in pig spermatozoa: a role of the hormone in the acquisition of fertilizing ability. Int $\mathrm{J}$ Androl. 2010; 33: 554-62.

29. Nixon B, Aitken RJ, McLaughlin EA. New insights into the molecular mechanisms of sperm-egg interaction. Cell Mol Life Sci. 2007; 64: 1805-23.

30. Clark GF. Molecular models for mouse sperm-oocyte binding. Glycobiology. 2011; 21:3-5.

31. Shur BD. Reassessing the role of protein-carbohydrate complementarity during sperm-egg interactions in the mouse. Int J Dev Biol. 2008; 52: 703-15.

32. Van Gestel RA, Brewis IA, Ashton PR, Brouwers JF, Gadella BM. Multiple proteins present in purified porcine sperm apical plasma membranes interact with the zona pellucida of the oocyte. Mol Hum Reprod. 2007; 13: 445-54.

33. Gadella BM. Sperm membrane physiology and relevance for fertilization. Anim Reprod Sci. 2008; 107: 229-36.

34. Perez Martinez SL, Menendez Helman RJ, Zitta KS, Brandelli A, Miranda PV. Characterization of human sperm $\mathrm{N}$-acetylglucosaminidase. Int J Androl. 2008; 31: 315-24.

35. Rajeev SK, Reddy KVR. Sperm membrane protein profiles of fertile and infertile men: identification and characterization of fertility-associated sperm antigen. Hum Reprod. 2004; 19: 234-42.

36. Sutovsky P. Sperm-egg adhesion and fusion in mammals. Expert Rev Mol Med. 2009; 11: 1-12.

37. Marcello MR, Evans JP. Multivariate analysis of male reproductive function in Inpp5b-/- mice reveals heterogeneity in defects in fertility, sperm-egg membrane interaction and proteolytic cleavage of sperm ADAMs. Mol Hum Reprod. 2010; 16: 492-505.

38. Bronson RA, Fusi FM, Calzi F, Doldi N, Ferrari A. Evidence that a functional fertilin-like ADAM plays a role in human sperm-oolemmal interactions. Mol Hum Reprod. 1999; 5: 433-40.

39. Frayne J, Hurd EAC, Hall L. Human tMDC III: a sperm protein with a potential role in oocyte recognition. Mol Hum Reprod. 2002; 8: 817-22.

40. Yamaguchi R, Muro Y, Isotani A, Tokuhiro K, Takumi K, Adham I, et al. Disruption of ADAM3 impairs the migration of sperm into oviduct in mouse. Biol Reprod. 2009; 81: 142-6.

41. Marín-Briggiler CI, Lapyckyj L, González Echeverría MF, Rawe VY, Alvarez Sedó C, Vazquez-Levin MH. Neural cadherin is expressed in human gametes and participates in sperm-oocyte interaction events. Int J Androl. 2010; 33: 228-39.

42. Cohen DJ, Busso D, Da Ros V, Ellerman DA, Maldera JA, Goldweic N, et al. Participation of cysteine-rich secretory proteins (CRISP) in mammalian sperm-egg interaction. Int J Dev Biol. 2008; 52: 737-42.

43. Cohen DJ, Da Ros VG, Busso D, Ellerman DA, Maldera JA, Goldweic N, et al. Participation of epididymal cysteine-rich secretory proteins in sperm-egg fusion and their potential use for male fertility regulation. Asian J Androl. 2007; 9: 528-32.

44. Busso D, Cohen DJ, Hayashi M, Kasahara M, Cuasnicu PS. Human testicular protein TPX1/CRISP-2: localization in spermatozoa, fate after capacitation and relevance for gamete interaction. Mol Hum Reprod. 2005; 11: 299-305.
45. Zhang J, Wu J, Huo R, Mao Y, Lu Y, Guo X, et al. ERp57 is a potential biomarker for human fertilization capability. Mol Hum Reprod. 2007; 13: 633-9.

46. Williams KM, Ford WCL. Effects of Ca-ATPase inhibitors on the intracellular calcium activity and motility of human spermatozoa. Int J Androl. 2003; 26: 366-75.

47. Aitken RJ, Baker MA. The role of proteomics in understanding sperm cell biology. Int J Androl. 2008; 31: 295-302.

48. Sachdeva G, Gadkar S, Shah CA, Kholkute SD, Puri CP. Characterization of a critical region in the hormone binding domain of sperm progesterone receptor. Int J Androl. 2005; 28: 120-4.

49. Shah C, Modi D, Sachdeva G, Gadkar S, D'Souza S, Puri C. N-terminal region of progesterone receptor B isoform in human spermatozoa. Int J Androl. 2005; 28: 360-71.

50. Capkova J, Elzeinova F, Novak P. Increased expression of secretory actin-binding protein on human spermatozoa is associated with poor semen quality. Hum Reprod. 2007; 22: 1396-404.

51. Singleton S, Zalensky A, Doncel GF, Morshedi M, Zalenskaya IA. Testis/sperm-specific histone $2 \mathrm{~B}$ in the sperm of donors and subfertile patients: variability and relation to chromatin packaging. Hum Reprod. 2007; 22: 743-50.

52. Oliva R. Protamines and male infertility. Hum Reprod Update. 2006; 12: 417-35.

53. Hammadeh M, Hamad M, Montenarh M, Fischer-Hammadeh C. Protamine contents and P1/P2 ratio in human spermatozoa from smokers and non-smokers. Hum Reprod. 2010; 25: 2708-20.

54. Torregrosa N, Dominguez-Fandos D, Camejo MI, Shirley CR, Meistrich ML, Ballesca JL, et al. Protamine 2 precursors, protamine 1/protamine 2 ratio, DNA integrity and other sperm parameters in infertile patients. Hum Reprod. 2006; 21: 2084-9.

55. Tavalaee M, Razavi S, Nasr-Esfahani MH. Influence of sperm chromatin anomalies on assisted reproductive technology outcome. Fertil Steril. 2009; 91: 1119-26.

56. Thimon V, Frenette G, Saez F, Thabet M, Sullivan R. Protein composition of human epididymosomes collected during surgical vasectomy reversal: a proteomic and genomic approach. Hum Reprod. 2008; 23: 1698-707.

57. Zhang J, Ding X, Bian Z, Xia Y, Lu C, Wang S, et al. The effect of anti-eppin antibodies on ionophore A23187-induced calcium influx and acrosome reaction of human spermatozoa. Hum Reprod. 2010; 25: 29-36.

58. Tollner TL, Yudin AI, Treece CA, Overstreet JW, Cherr GN. Macaque sperm coating protein DEFB126 facilitates sperm penetration of cervical mucus. Hum Reprod. 2008; 23: 2523-34.

59. Li Y, Sosnik J, Brassard L, Reese M, Spiridonov NA, Bates TC, et al. Expression and localization of five members of the testis-specific serine kinase (Tssk) family in mouse and human sperm and testis. Mol Hum Reprod. 2011; 17: 42-56

60. Yang R-B, Au H-K, Tzeng C-R, Tsai M-T, Wu P, Wu Y-C, et al. Characterization of a novel cell-surface protein expressed on human sperm. Hum Reprod. 2010; 25: 42-51.

61. Ignotz GG, Lo MC, Perez CL, Gwathmey TM, Suarez SS. Characterization of a fucose-binding protein from bull sperm and seminal plasma that may be responsible for formation of the oviductal sperm reservoir. Biol Reprod. 2001; 64: $1806-11$

62. Lefebvre J, Boileau G, Manjunath P. Recombinant expression and affinity purification of a novel epididymal human sperm-binding protein, BSPH1. Mol Hum Reprod. 2009; 15: 105-14.

63. Gwathmey TM, Ignotz GG, Mueller JL, Manjunath P, Suarez SS. Bovine seminal plasma proteins PDC-109, BSP-A3, and BSP-30-kDa share functional roles in storing sperm in the oviduct. Biol Reprod. 2006; 75: 501-7.

64. Moura AA, Chapman DA, Koc H, Killian GJ. A comprehensive proteomic analysis of the accessory sex gland fluid from mature Holstein bulls. Anim Reprod Sci. 2007; 98: 169-88.

65. Lachance C, Fortier M, Thimon V, Sullivan R, Bailey JL, Leclerc P. Localization of Hsp60 and Grp78 in the human testis, epididymis and mature spermatozoa. Int J Androl. 2010; 33: 33-44.

66. Gyamera-Acheampong C, Mbikay M. Proprotein convertase subtilisin/kexin type 4 in mammalian fertility: a review. Hum Reprod Update. 2009; 15: 237-47.

67. Nothwang HG, Schindler J. Two-Dimensional Separation of Membrane Proteins by 16-BAC-SDS-PAGE. In: Peirce MJ, Wait R, editors. Membrane Proteomics. Totowa, New Jersey, USA: Humana press. 2009:269-77.

68. Learmonth M, Aitken A. Protein Identification by In-Gel Digestion and Mass Spectrometric Analysis. In: Walker JM, editor. The Proteomics Protocols handbook. Totowa, New Jersey, USA: Humana press. 2005: 311-4. 